\title{
Synthesis of activated carbon doped with transition metals for hydrogen storage
}

\author{
Nazlina Ya'aini ${ }^{1}$, Arjun Pillay A/L Gopala Krishnan ${ }^{1,2}$ and Adnan Ripin ${ }^{1,2^{*}}$ \\ ${ }^{1}$ Centre of Hydrogen Energy, Institute of Future Energy, Universiti Teknologi Malaysia, 81310 Johor \\ Bahru, Malaysia \\ ${ }^{2}$ School of Chemical and Energy Engineering, Faculty of Engineering, Universiti Teknologi \\ Malaysia, 81310 Johor Bahru, Malaysia
}

\begin{abstract}
Carbon materials with high porosity and surface area such as activated carbons with a combination of metal possess great materials to obtain maximum hydrogen adsorption via the hydrogen spillover effect. The properties of activated carbon doped with metals (copper, nickel and palladium) were studied to evaluate the capacity of hydrogen sorption on the materials. Characteristics of the activated carbon doped with copper (AC$\mathrm{Cu}$ ), nickel (AC-Ni) and palladium (AC-Pd) were evaluated using particle density test, Fourier transform infrared spectroscopy (FTIR), x-ray diffraction (XRD) and surface and pore analysis (BET). The performance of hydrogen adsorption of the materials was carried out at different pressures of 50, 100 and 150 psi. Characterization of the materials shows that FTIR spectroscopy manage to detect surface functional groups meanwhile the carbon structure and metal content was determined using XRD. BET analysis shows the presence of oxygen groups was decrease the specific surface area whereas the presence of transition metals had increased the surface area. Hydrogen adsorption test at 150 psi indicates that oxygen groups are not a good adsorption characteristic with only a maximum of 0.39 wt $\%$ of hydrogen was adsorbed compared to pristine activated carbon's 0.42 $\mathrm{wt} \%$ at $150 \mathrm{psi}$. The presence of transition metals, copper, nickel and palladium increased the overall hydrogen uptake with $0.52 \mathrm{wt} \%, 0.44 \mathrm{wt} \%$ and $0.62 \mathrm{wt} \%$ respectively at $150 \mathrm{psi}$.
\end{abstract}

\section{Introduction}

Demanding for green energy as an alternative to fossil fuels has risen significantly in the last few decades [1]. Hydrogen seems to be a promising element as an energy carrier due to its high energy density per unit mass with minimum impact on the environment [2]. In addition, hydrogen is considered green energy, because it can be generated from renewable sources such as photo-electrochemical, biological process and wind energy. Nevertheless, there are still challenges in the developing green energy from hydrogen. One of the challenges is to develop efficient and safe hydrogen storage and transportation. When comparing with the

\footnotetext{
* Corresponding author: $\underline{\text { r-adnan@utm.my }}$
} 
gaseous and liquid phases of hydrogen storage, solid-state hydrogen storage is favoured when the safety and high volumetric capacity are considered [2].

In the automobile industry, hydrogen storage is a key enabling technology for the advancement of hydrogen fuel-cell vehicles. Storing enough hydrogen (4-10 kg) on-board a light-duty vehicle to achieve a 300 to 500 mile driving range is a significant challenge. On a weight basis, hydrogen has nearly three times the energy content of gasoline when comparing lower heating values that are $33 \mathrm{kWh} / \mathrm{kg}$ for $\mathrm{H}_{2}$ compared to $12 \mathrm{kWh} / \mathrm{kg}$ for gasoline. However, in terms of volume, the situation is reversed where approximately $1.3 \mathrm{kWh} / \mathrm{L}$ for 700 bar $\mathrm{H}_{2}$ compared to $8.8 \mathrm{kWh} / \mathrm{L}$ for gasoline at $15^{\circ} \mathrm{C}$. Besides the factor of energy density, hydrogen storage systems face obstacles with regards to cost, charge/discharge rates, fuel quality, durability, efficiency and safety which may hinder the widespread commercialization of hydrogen fuel-cell vehicles. In order to operate a hydrogen fuel-cell vehicle that can be fully-functional and show cost-effective performances on the road, the United States Department of Energy (DOE) have proposed critical properties that a hydrogen storage material should possess which include that it be lightweight, inexpensive and readily available, exhibit rapid sorption kinetics, accommodating high volumetric and gravimetric densities for hydrogen, low temperature dissociation, appropriate thermodynamic properties, easy activation, high reversibility and long-term cycling stability [3].

Many studies have been carried out to determine the potential of propose materials for hydrogen storage, including (i) metal hydrides and (ii) hydrogen adsorption in metal-organic frameworks (MOFs), (iii) carbon-based systems, (iv) porous materials and (v) complex hydrides [4]. Carbon materials such as carbon nanotubes, graphene, activated carbons and carbon nanofibers are widely used in the research of hydrogen storage. Advantages of using carbon materials for hydrogen storage are i) high hydrogen storage capacities in the carbon nanostructures, (ii) cheap, (iii) readily available and iv) lightweight [5].

The modification of carbon materials with doping of transition metals potentially enhance the hydrogen capacity at ambient conditions [6]. By adding these metals to the carbon structures, a composite material that combines both physical and chemical adsorption processes are obtained. This type of activation can be justified via the spillover mechanism which involves the dissociative chemisorption of hydrogen molecules on the transition metals that results in the formation of hydrogen atoms. This is because high hydrogen adsorption capacities at practical temperatures rely on the chemical reaction between carbon and hydrogen atoms [6].

This paper intends to investigate the potential of the activated carbon doped with transition metals of Copper, Nickel and Palladium to enhance the hydrogen uptake capacities for the solid-state hydrogen storage in automobiles applications. The research work requires synthesizing and characterizing the physical and chemical properties of pristine, acid-treated and metal-doped activated carbons materials. Further investigation was conducted to analyse the hydrogen adsorption capacity of these materials. Structure of this paper is divided into four sections; Section 2 explains methods for synthesizing, characterizing and testing the materials. Section 3 represents the results of analyses and discussion. Finally, Section 4 concludes and further recommendations for improving the research work. 


\section{Materials and Methods}

\subsection{Synthesis of Materials}

\subsubsection{Acid treatment}

Activated carbon was prepared and treated with nitric acid $\left(\mathrm{HNO}_{3}\right)$ to modify the surface structure by introducing oxygen functional groups. The oxides on the carbon surface can facilitate the doping of transition metals. $30 \mathrm{~g}$ of activated carbon was weighed and added into a round-bottom flask. Nitric acid $(65 \%, 17.15 \mathrm{ml})$ was slowly added to $62.5 \mathrm{ml}$ deionized water and the final volume of the solution was adjusted to $250 \mathrm{ml}$ with deionized water. The solution slowly poured into the round-bottom flask to mix with the activated carbon. The round-bottom flask was kept under reflux boiling at $125^{\circ} \mathrm{C}$ for 30 hrs with the rotation speed of $750 \mathrm{rpm}$. The resulting materials were filtered and extensively washed with distilled water using vacuum filtration in a Büchner flask until the cleaning water $\mathrm{pH}$ was approximately 7 . The sample was placed in a Petri dish and oven dried at $110^{\circ} \mathrm{C}$ for $12 \mathrm{hrs}$. The dried sample was cool at room temperature for 30 mins and labelled as Untreated AC.

\subsubsection{Transition Metal Doping}

In, the activated carbon samples were doped with transition metals using the wetness impregnation method. The product from the acid treatment, Untreated AC was used as the activated carbon samples for metal doping. $25 \mathrm{~g}$ of precursor, copper (II) nitrate trihydrate $\mathrm{Cu}\left(\mathrm{NO}_{3}\right)_{2} .3 \mathrm{H}_{2} \mathrm{O}$ was mixed with demineralized water in a $250 \mathrm{ml}$ volumetric flask. The activated carbon samples were placed into a $500 \mathrm{ml}$ beaker and the precursor solution was slowly poured to mix with the activated carbon in the beaker. The mixture was left to mix under agitation with a $750 \mathrm{rpm}$ rotation speed for $16 \mathrm{hrs}$. The mixture was filtered via vacuum filtration in a Büchner flask. The filtrates were placed in a Petri dish and oven dried at $100^{\circ} \mathrm{C}$ for $6 \mathrm{hrs}$. After drying, the sample was placed under room temperature to cool down for 30 mins. The sample was then collected and labelled as AC-Cu. The same procedures were repeated using other precursors of palladium (II) nitrate dihydrate, $\mathrm{Pd}\left(\mathrm{NO}_{3}\right)_{2} .2 \mathrm{H}_{2} \mathrm{O}(\mathrm{AC}-\mathrm{Pd})$ and nickel (II) nitrate hexahydrate, $\mathrm{Ni}\left(\mathrm{NO}_{3}\right)_{2} \cdot 6 \mathrm{H}_{2} \mathrm{O}(\mathrm{AC}-\mathrm{Ni})$.

\subsection{Characterization}

Pristine, acid-treated and metal-doped activated carbons were characterized using Quantachrome Multipycnometer, Fourier transform infrared spectroscopy (FTIR), x-ray diffraction (XRD) and Brunauer, Emmet and Teller (BET). Particle density test was conducted to determine sample volume and particle density. $1 \mathrm{~g}$ of the sample, AC was weighed and placed in a container. The sample was slowly added into the test chamber of the multi pycnometer. Helium gas was admitted into the system and the values of the first pressure, $\mathrm{P} 1$ and the second pressure, $\mathrm{P} 2$ were recorded.

FTIR spectroscopy was carried out to determine the functional groups present on the surface of the activated carbon samples. The analysis was conducted using the model of Perkin-Elmer Spectrum GX FTIR Spectrometer with a wavenumber scan rate ranging from $0 \mathrm{~cm}^{-1}$ to $4500 \mathrm{~cm}^{-1}$. AC was weighed to precisely $0.001 \mathrm{~g}$ while potassium bromide, $\mathrm{KBr}$ as a diluent was weighed at precisely $0.1 \mathrm{~g}$. With a mass ratio of $\mathrm{KBr}$ to $\mathrm{AC}$ at $1: 100$, the mixture was further ground and mixed thoroughly. A hydraulic pump was used to 
squash the mixture and form a transparent disc. The disc was then placed into the FTIR sample holder and the analysis was allowed to run.

XRD analysis was performed to study the surface morphology and determine the average particle size of a sample. For this analysis, the parameters used were $\mathrm{Cu} \mathrm{K \alpha}$ radiation with a wavelength of $20 \mathrm{M}$ and $40 \mathrm{kV}$ at a scanning angle of $2 \theta$. The ranges of measurement used were from $0^{\circ}$ to $100^{\circ}$ using Smart-Lab from Rigaku model.

Surface area and pore analysis were conducted to identify the specific surface area and total pore volume of the samples. The surface area was determined by the Brunauer, Emmet and Teller (BET) theory. On the other hand, the total pore volume was estimated by the nitrogen-adsorption isotherm while the micropore volume and mesopore surface area were determined using t-Plot by Lippens and de Boer. Characterizations of the samples were done using Micromeritics ASAP 2020. Before running the analysis, the samples were first degassed at $300^{\circ} \mathrm{C}$ for $4 \mathrm{hrs}$. The textural properties and calculations of the samples were determined based on $\mathrm{N}_{2}$ adsorption-desorption isotherm.

\subsection{Hydrogen Adsorption Test}

The adsorption test was conducted using a custom built volumetric differential pressure apparatus as shown in Fig. 1 below. The purpose was to determine the pressure difference detected by the transmitter. This pressure difference was caused by the adsorption of hydrogen due to the presence of AC samples in the sample chamber. The values of pressure difference were then used to calculate the hydrogen adsorption capacity.

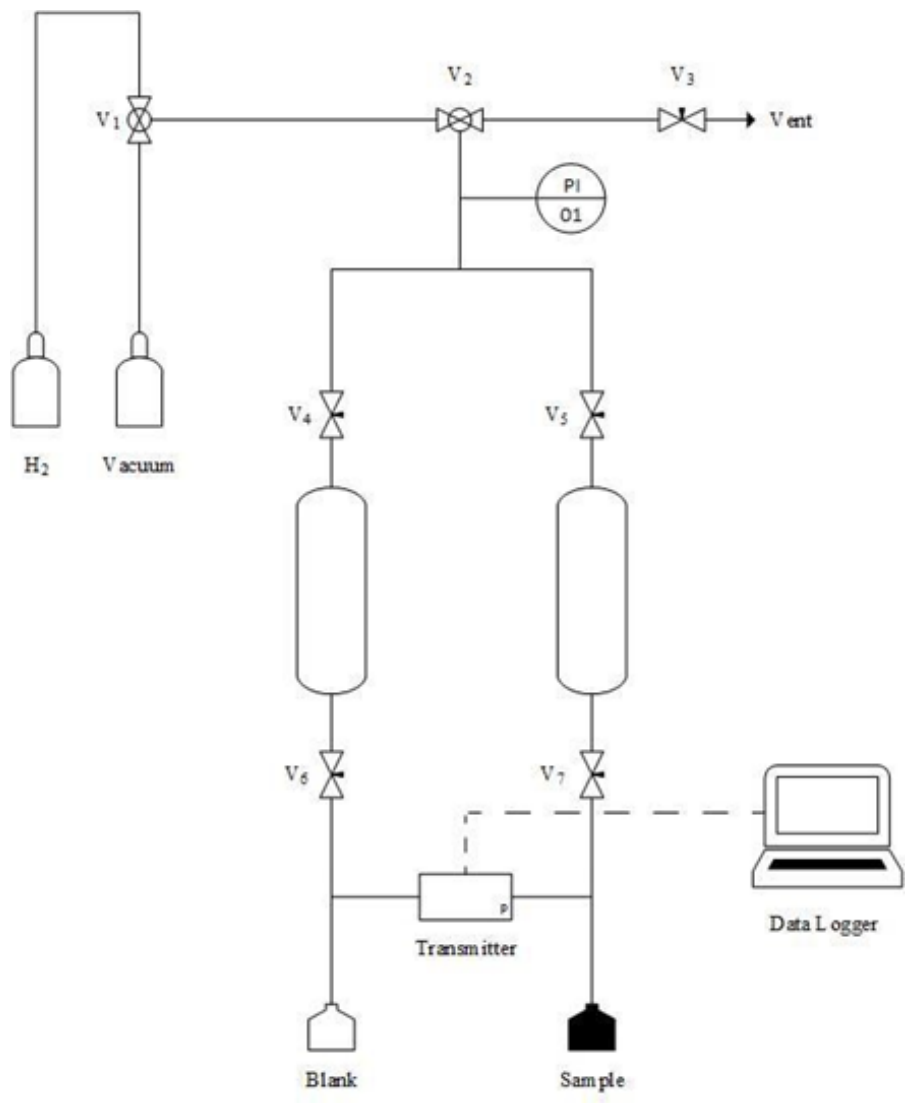


Fig. 1. Volumetric differential pressure apparatus.

\section{Results and Discussion}

\subsection{Particle Density Test}

The particle density of prepared materials is shown in Table 1. AC depicted a lower density value of $1781.60 \mathrm{~kg} / \mathrm{m}^{3}$ compared to its standard density of $2000-2100 \mathrm{~kg} / \mathrm{m}^{3}$. This may be due to trapped air particles in the carbon matrix that affected the actual density. Untreated AC showed the highest particle density at $1993.35 \mathrm{~kg} / \mathrm{m}^{3}$, due to the presence of new oxygen functional groups in the carbon matrix which has decreased the pore volume block the micropores structure [7]. Conversely, the metal-doped activated carbon samples show improved particle volume but lower particle density. In contrast to the oxygen functional groups, the transition metal groups are larger in size but they act as a catalyst on the surface of the carbon to facilitate the movement of small atomic particles such as helium gas to flow into the carbon matrix [8]. The smooth flow of helium gas enhanced the particle volume and subsequently reduce particle density.

Table 1. Particle density of samples

\begin{tabular}{ccccc}
\hline Sample & $\begin{array}{c}\text { Pressure, } \mathbf{P 1} \\
\mathbf{( p s i )}\end{array}$ & $\begin{array}{c}\text { Pressure, P2 } \\
\mathbf{( p s i )}\end{array}$ & Volume $\left(\mathbf{m}^{\mathbf{3}}\right)$ & $\begin{array}{c}\text { Particle Density } \\
\left(\mathbf{k g} / \mathbf{m}^{\mathbf{3}}\right)\end{array}$ \\
\hline AC & 15.292 & 7.982 & $1.1282 \times 10^{-7}$ & 1781.60 \\
Treated AC & 15.288 & 7.988 & $1.0240 \times 10^{-7}$ & 1993.35 \\
AC-Cu & 15.312 & 7.977 & $1.3330 \times 10^{-7}$ & 1500.38 \\
AC-Ni & 15.282 & 7.966 & $1.2669 \times 10^{-7}$ & 1594.43 \\
AC-Pd & 15.298 & 7.985 & $1.1300 \times 10^{-7}$ & 1752.37 \\
\hline
\end{tabular}

\subsection{Fourier Transform Infrared Spectroscopy}

Fig. 2 represents the FTIR spectra for all the treated AC samples and the spectra showed similar results for all the AC samples. In general, all the samples show similar spectra especially the samples after acid treatment. The most obvious vibration is the broad bands between $3648 \mathrm{~cm}^{-}$and $2995 \mathrm{~cm}^{-}$in the spectrum which may be attributed to the presence of surface groups such as hydroxyl, phenol, carboxylic acid derivatives as well as the presence of physically absorbed water molecules on the carbon surface. These bands are formed via $\mathrm{O}-\mathrm{H}$ stretching and the formation of hydroxyl groups as well as adsorbed water on the carbon surface [9]. The presence of hydroxyl groups may also be due to the usage of phosphoric acid, H3PO4 as the main acid for the activation of carbon.

For all samples, there are noticeable peaks between the range of $1697 \mathrm{~cm}$ to $458 \mathrm{~cm}^{-1}$. The band around $1750 \mathrm{~cm}^{-1}$ to $1550 \mathrm{~cm}^{-1}$ is possibly the stretching vibration $\mathrm{C}=\mathrm{O}$ in carboxyl, aldehyde, ketone or lactone group. In addition, the band around $1200 \mathrm{~cm}^{-1}$ is typically due to the presence of $\mathrm{C}-\mathrm{O}$ groups. In activated carbons, there are certainly the presence of $\mathrm{C}=\mathrm{C}$ bonds and these groups can be seen by stretch vibrations in the spectrum within the range of $1700 \mathrm{~cm}^{-}$to $1600 \mathrm{~cm}^{-1}$. Due to the fact that these activated carbon samples are chemically prepared by $\mathrm{KOH}$, the band in the region $950 \mathrm{~cm}^{-1} 1150 \mathrm{~cm}$ may be caused by the potassium-containing groups. Apart from those, there is also a very obvious peak between $2250 \mathrm{~cm}^{-}$and $2350 \mathrm{~cm}^{-}$. This peak frequency in the IR spectra could be due to the presence of carbon dioxide, $\mathrm{CO}_{2}$ in the sample as the possible assignment of this stretch vibration [10].

For samples doped with metal, a prominent peak can be seen between $550 \mathrm{~cm}^{\text {to }} 400$ $\mathrm{cm}^{-}$. This could be due to the presence of metal elements within the sample. This statement is made due to the observation from several researches. For copper, the general $\mathrm{Cu}-\mathrm{N}$ band 
can be observed in the region of $550 \mathrm{~cm}^{-1}$ to $441 \mathrm{~cm}^{-1}$ and for palladium, Pd-N stretching vibrations can be observed at frequencies from $526 \mathrm{~cm}^{-1}$ to $436 \mathrm{~cm}^{-1}$ [11]. Next, for nickel, the $\mathrm{Ni}-\mathrm{N}$ stretching mode with probably some contribution from $\mathrm{Ni}-\mathrm{O}$ stretching, can be seen at around the $463 \mathrm{~cm}^{-1}$ band on the basis of high observed shift of $8 \mathrm{~cm}^{-1}$ [12]. However, for the FTIR analysis conducted in this experiment for nickel-doped activated carbon (AC-Ni), there are no visible stretching vibrations for the nickel IR frequency and this may be due to certain errors during the analysis such as contamination of sample and insufficient cleaning of equipment while conducting the analysis.

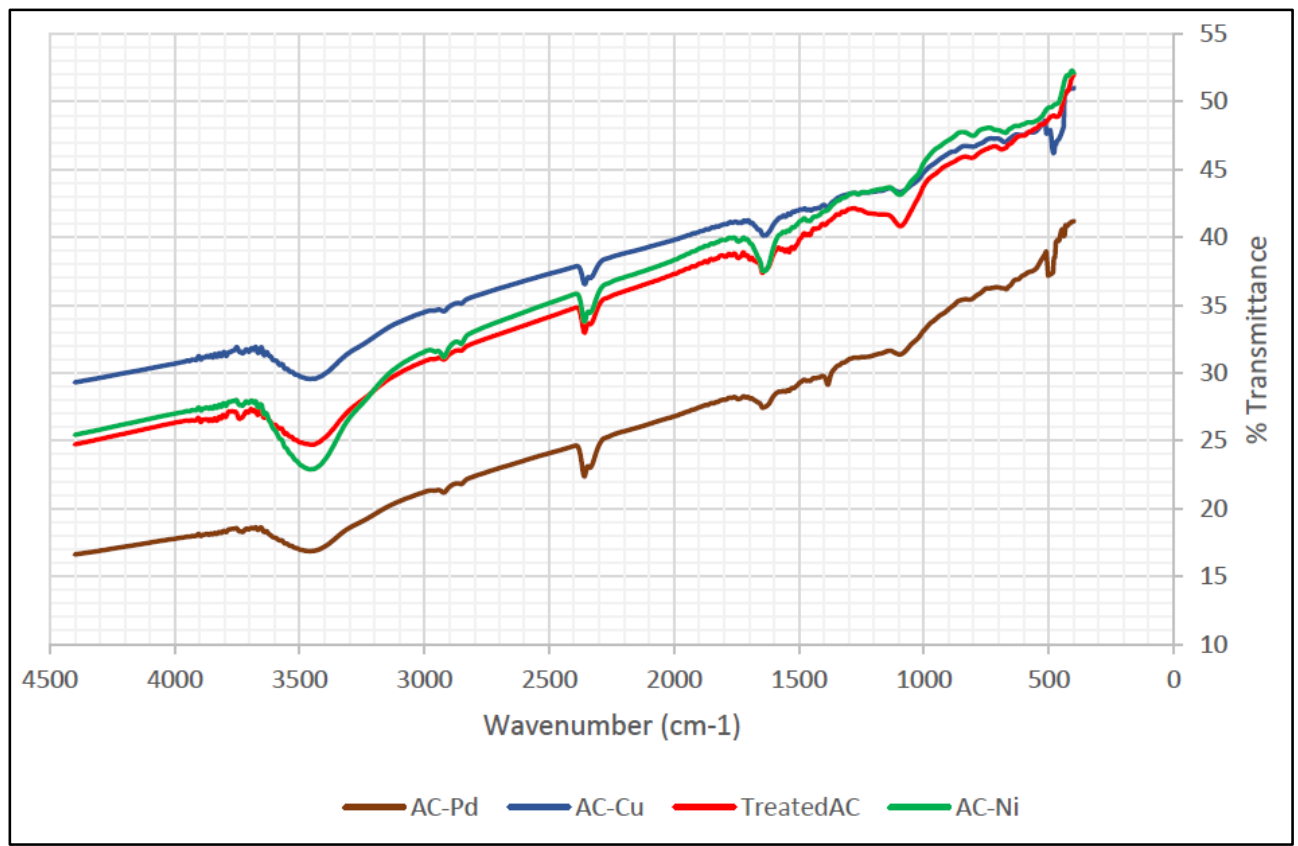

Fig. 2. FTIR spectra of treated AC samples

\subsection{X-Ray Diffraction}

Fig. 3. illustrates the XRD profile of AC-Pd. The similar pattern was also observed with the other AC samples. The peaks at around $2 \theta=24^{\circ}$ and $43^{\circ}$ indicate amorphous carbon structure. However, the short peak at $2 \theta=43.55^{\circ}$ refers to the presence of palladium metal. According to previous researches, the characteristics peaks of metal palladium are clearly observed in the metal-doped samples at around $2 \theta=46^{\circ}$ [13]. However, the peak is short signifying low intensity and this may be due to the low metal content. The peaks at $2 \theta=40.078^{\circ}, 43.55^{\circ}$ and $79.22^{\circ}$ correspond to reflections (111), (200) and (220) and this result coincides with the findings from other research: the palladium metal d-spacing values correspond to (111), (200) and (220) which indicates the face-centred cubic (fcc) structure of palladium metal as well as other transition metals [14]. 


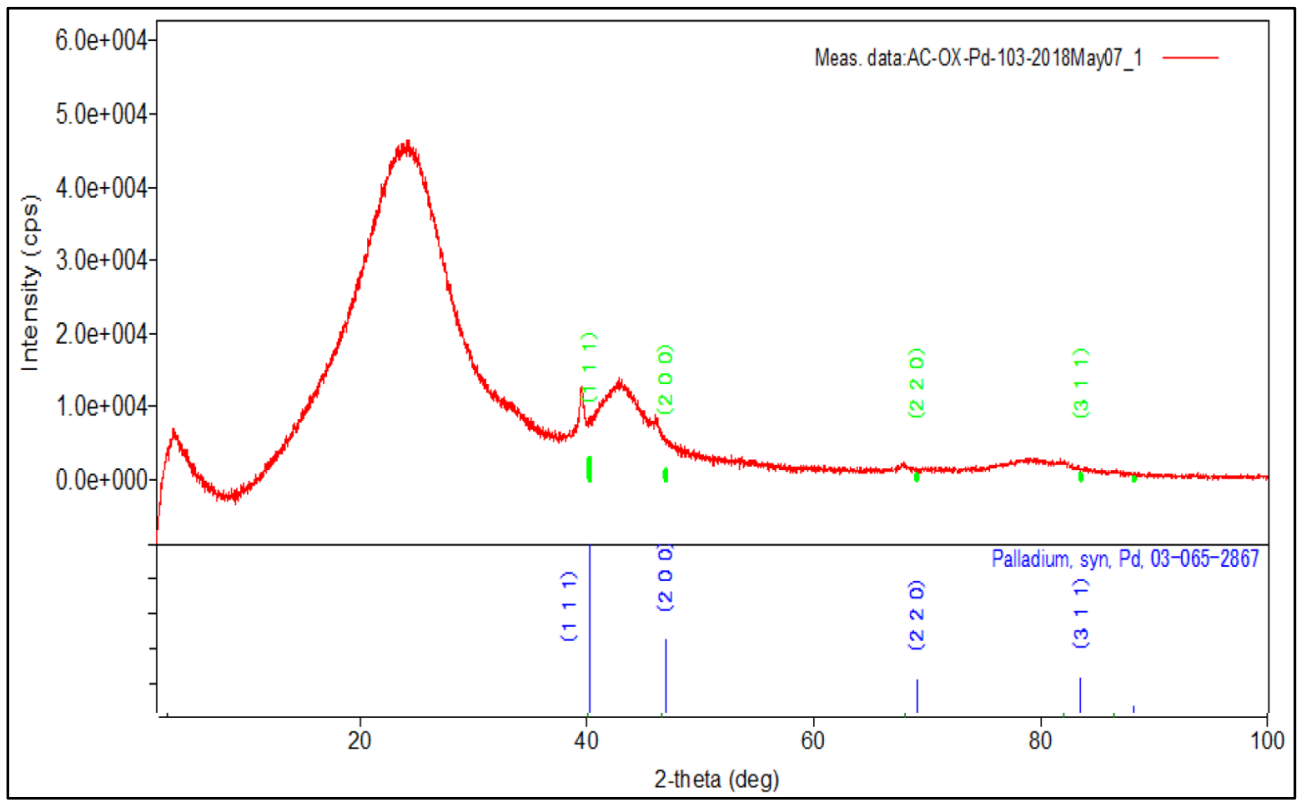

Fig. 3. XRD spectrum of AC-Pd

\subsection{Surface Area and Pore Analysis}

Table 2 represents the surface properties of AC samples using BET analysis. Based on the results, AC has the highest specific surface area and total pore volume at $1012 \mathrm{~m}^{2} / \mathrm{g}$ and $0.42 \mathrm{~cm}^{3} / \mathrm{g}$ respectively. However, Treated AC shows the lowest value at $1011 \mathrm{~m}^{2} / \mathrm{g}$. The lower specific surface area and total pore volume are due to the blocking effect caused by the presence of new functional groups by the oxidation reactions and the erosion of carbon skeletal structure [15]. The reduction of porous characteristics of the carbon is probably due to stearic hindrance effect created by the oxygen functional groups at the entrance of micropores after acid treatment was conducted.

Table 2. Textual properties of activated carbons

\begin{tabular}{lccccc}
\hline ACParameters & AC & Treated AC & AC-Cu & AC-Ni & AC-Pd \\
\hline S BET $\left(\mathrm{m}^{2} / \mathrm{g}\right)$ & 1012 & 1011 & 1016 & 1013 & 1019 \\
Pore volume $\left(\mathrm{cm}^{3} / \mathrm{g}\right)$ & 0.42 & 0.40 & 0.41 & 0.40 & 0.41 \\
\hline
\end{tabular}

Generally, the presence of metal nanoparticles in the carbon matrix promotes the increase in specific surface area as can be seen from Table 2 with values of $1016.1 \mathrm{~m}^{2} / \mathrm{g}, 1013.4$ $\mathrm{m}^{2} / \mathrm{g}$ and $1018.9 \mathrm{~m}^{2} / \mathrm{g}$ for $\mathrm{AC}-\mathrm{Cu}, \mathrm{AC}-\mathrm{Ni}$ and $\mathrm{AC}-\mathrm{Pd}$ respectively. However, the pore volumes remain similar to the pore volume of AC. In terms of specific surface area and micropore volume, Park and Lee [16] claims that the micropores volume of metal-decorated was increased due to well-dispersed metal nanoparticles on the carbon surface which does not contribute to pore blocking. Based on the results of activated carbon with the presence of transition metal, it can be concluded that the presence of these metal nanoparticles on a well-dispersed activated carbon surface leads to a high specific surface area and thus increases the hydrogen adsorption capacity. 


\subsection{Hydrogen Adsorption Test}

Fig. 4 illustrates the hydrogen adsorption capacity of each carbon sample at different test pressures of $50 \mathrm{psi}, 100 \mathrm{psi}$ and $150 \mathrm{psi}$. In general, the graph shows linear relationships between the pressure and the hydrogen adsorption capacity. As the pressure in the test chamber is increased from 50 psi to $150 \mathrm{psi}$, the overall storage capacity also increases. This trend can be explained by both physisorption and chemisorption processes as well as the restructuring of the carbon particles. At lower pressure, both physisorption and chemisorption processes have effected on the hydrogen uptake in the micropores of these carbon samples. Whereas at high pressures, physisorption and the restructuring of carbon particles may have enhanced the storage capacity of these carbons. This similar discussion on the physisorption of hydrogen in activated carbons is also found in the study of Jimenez et al. [17].

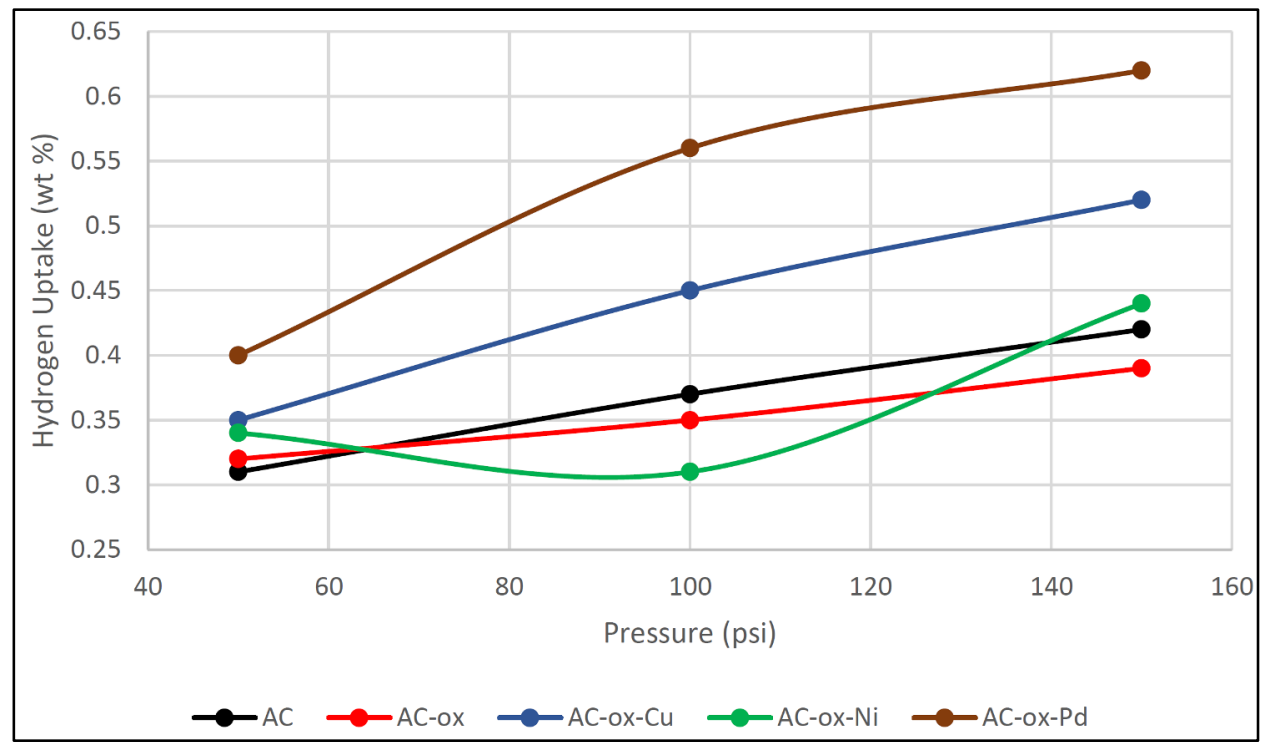

Fig. 4. Hydrogen adsorption capacity at different pressures for each activated carbon sample

In the comparison between pure and acid-treated activated carbon, the Treated AC sample initially showed slightly higher hydrogen storage capacity at $0.32 \mathrm{wt} \%$ compared to $\mathrm{AC}$, $0.31 \mathrm{wt} \%$. However, as the pressure increased, the hydrogen uptake for Treated AC was only $0.39 \mathrm{wt} \%$ compared to $\mathrm{AC}, 0.42 \mathrm{wt} \%$. This proves that acid-treatment and the addition of oxygen functional groups did not facilitate the hydrogen uptake. In addition, it reduces due to several factors such as the stearic hindrance effect, weak oxygen to hydrogen interactions and an increase of solid weight for oxygenated compounds. This result agrees with the findings obtained by Zhao et al. [18]. They revealed that oxygen-containing functional groups give a negative effect on hydrogen uptake in activated carbons because of the repulsive interactions between the hydrogen molecules and the oxygen groups. Similar results were obtained by M. J. Bleda-Martínez et al. [19], which stated that oxygen groups do not contribute to hydrogen storage.

In general, metal-doped activated carbons show higher hydrogen uptake compared to pristine and acid-treated activated carbon with AC-Pd having the highest value of hydrogen absorbed, $0.62 \mathrm{wt} \%$ at $150 \mathrm{psi}$ operating pressure. High of hydrogen storage capacities of the metal-doped activated carbon is due to the strong transition metal bond to the carbon surface which enhances the hydrogen spillover mechanism and further 
facilitate hydrogen dissociative and chemisorption activities [20]. Furthermore, the presence of transition metal may improve the hydrogen sorption capacity by allowing difference surface adsorbent to interact or bonds. Palladium metal sample (AC-Pd) show the highest hydrogen uptake meanwhile nickel metal sample (AC-Ni) did portray a slightly different trend as the sample only obtained $0.31 \mathrm{wt} \%$ of hydrogen uptake at $100 \mathrm{psi}$. This could be due to the agglomeration of nickel nanoparticles on the carbon surface which has blocked the hydrogen atoms from entering the micropores. Similar studies were obtained by Aksoylu et al. [21]. The low of hydrogen adsorption on the nickel-doped on activated carbon occurred due to the accumulation of the transition metal during the impregnation procedure which caused uneven dispersion of metal nanoparticles on the carbon surface.

Fig. 5. depicts the relationship between the hydrogen uptake and the specific surface area calculated from BET analysis for each carbon sample at different pressures of $50 \mathrm{psi}$, $100 \mathrm{psi}$ and $150 \mathrm{psi}$. The general trend of the curve shows a linear relationship between the hydrogen uptake and specific surface area. As the specific surface area increases, the hydrogen uptake of the activated carbon samples also increases. Similar findings were studied by Luzan and Talyzin [22]. The hydrogen adsorption had a linear correlation with the BET surface area and the total pore volume. As the specific surface area of the carbon sample increases, there are more sites for adsorption to occur, consequently improving hydrogen storage capacity.

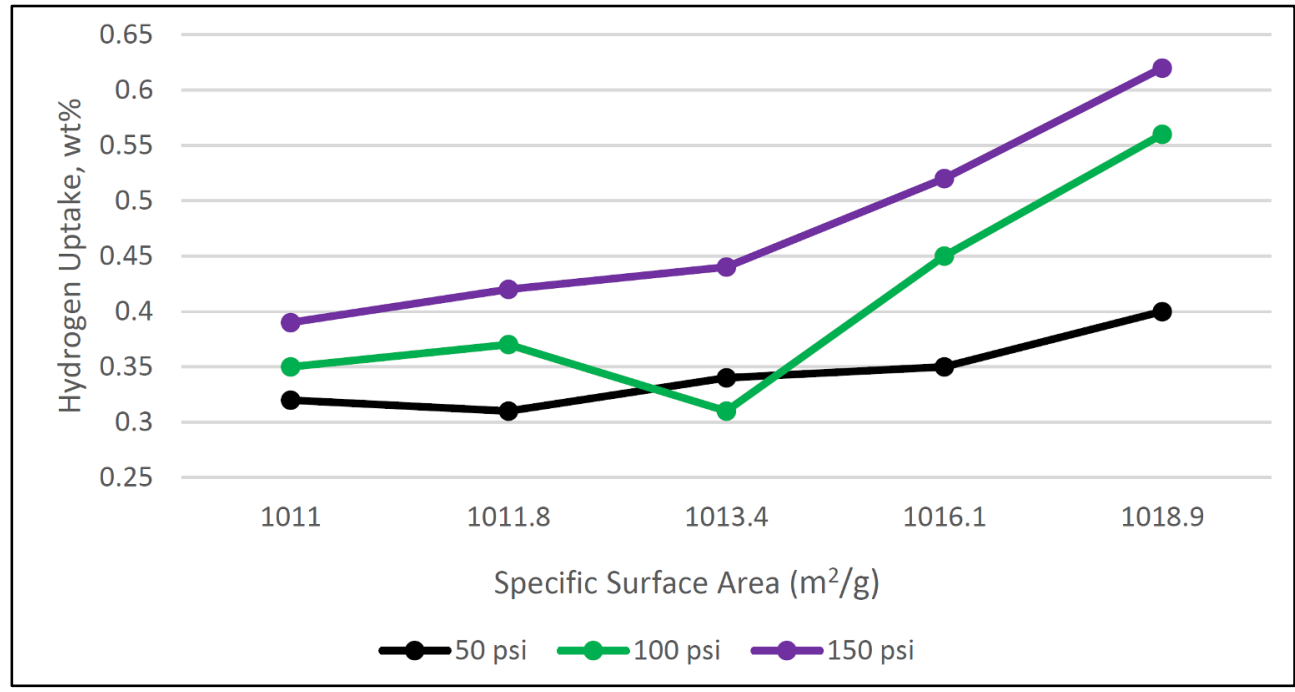

Fig. 5. Graph of hydrogen uptake against the specific surface area

\section{Conclusions}

In conclusion, preparation, characterization and performance testing of the activated carbon doped with transition metals $(\mathrm{Co}, \mathrm{Ni}, \mathrm{Pd})$ were successfully determined the capacity of hydrogen uptake for hydrogen storage. The analyses could determine the surface characteristics of the AC samples by identifying the presence of oxygen functional groups, transition metal content, amorphous carbon structure as well as evaluate the BET surface area and pore volumes. The hydrogen adsorption test was conducted on all samples at different pressures of $50 \mathrm{psi}, 100 \mathrm{psi}$ and $150 \mathrm{psi}$. The trend shows that as pressure increases, the hydrogen uptake also increases accordingly. The hydrogen adsorption capacity for metal-doped carbon samples showed better results compared to pristine and 
acid-treated activated carbon. This is because the presence of transition metals that act as catalysts are able to facilitate the dissociation of hydrogen molecules to hydrogen atoms via the spillover mechanism thus increasing the hydrogen uptake. Palladium metal shows the highest hydrogen uptake at $0.62 \mathrm{wt} \%$ at $150 \mathrm{psi}$. This result indicates that existance of the dissociative chemisorption of dihydrogen onto palladium metal followed by migration of hydrogen atoms on the surface of activated carbon and subsequently diffuse away from the site by hydrogen spillover mechanism. This further proves the capability of palladium as a strong catalyst for hydrogen adsorption. In contrast, low hydrogen uptake values were observed from the acid-treated activated carbon sample a range of $0.32 \mathrm{wt} \%$ to $0.39 \mathrm{wt} \%$. This value is even lower than the pure activated carbon samples and this may be due to stearic hindrance effect caused by the presence of oxygen functional groups which block the pores and reduce hydrogen storage capacity. Thus, this study suggests that the hydrogen storage capacity is dependent on the operating pressure and presence of metal as a catalyst to increase the hydrogen uptake capacity.

We acknowledge financial support by the Universiti Teknologi Malaysia for the Research University Grant (vote number 04G13).

\section{References}

1. V. D. Camiola, R. Farchioni, T. Cavallucci, A. Rossi, V. Pellegrini, and V. Tozzini, 2, 2 (2015).

2. T. Y. Wei, K. L. Lim, Y. S. Tseng, and S. L. I. Chan, Renew. Sustain. Energy Rev. 79, 1122 (2017).

3. Target Explanation Document: Onboard Hydrogen Storage for Light-Duty Fuel Cell Vehicles (2015).

4. R. Krishna, E. Titus, M. Salimian, O. Okhay, S. Rajendran, A. Rajkumar, J. M. G. Sousa, A. L. C. Ferreira, J. Campos, and J. Gracio, in Hydrog. Storage (InTech, 2012).

5. T. Ramesh, N. Rajalakshmi, and K. S. Dhathathreyan, J. Energy Storage 4, 89 (2015).

6. I. Rossetti, G. Ramis, A. Gallo, and A. Di Michele, Int. J. Hydrogen Energy 40, 7609 (2015).

7. M. Inagaki and J. M. D. Tascón, Interface Sci. Technol. 7, 49 (2006).

8. S. K. Konda and A. Chen, Mater. Today 19, 100 (2016).

9. S. M. Yakout and G. Sharaf El-Deen, Arab. J. Chem. 9, S1155 (2016).

10. S. M. Anisuzzaman, C. G. Joseph, W. M. A. B. W. Daud, D. Krishnaiah, and H. S. Yee, Int. J. Ind. Chem. 6, 9 (2015).

11. J. R. Durig, R. Layton, D. W. Sink, and B. R. Mitchell, Spectrochim. Acta 21, 1367 (1965).

12. C. Rocchicciolideltcheff, P. Gouzerh, Y. Jeannin, and F. Valentini, J. Mol. Struct. - J MOL STRUCT 49, 83 (1978).

13. N. Bader and A. Ouederni, J. Energy Storage 13, 268 (2017).

14. S. Navaladian, B. Viswanathan, T. K. Varadarajan, and R. P. Viswanath, Nanotechnology 19, 45603 (2008).

15. M. Seredych and T. Bandosz, Fuel Process. Technol. 91, 693 (2010). 
16. S.-Y. Lee and S.-J. Park, J. Solid State Chem. 194, 307 (2012).

17. V. Jiménez, P. Sánchez, J. A. Díaz, J. L. Valverde, and A. Romero, Chem. Phys. Lett. 485, 152 (2010).

18. X. B. Zhao, B. Xiao, A. J. Fletcher, and K. M. Thomas, J. Phys. Chem. B 109, 8880 (2005).

19. M. J. Bleda-Martínez, J. M. Pérez, A. Linares-Solano, E. Morallón, and D. CazorlaAmorós, Carbon N. Y. 46, 1053 (2008).

20. P. Badenes, L. Daza, I. Rodriguez-Ramos, and A. Guerrero-Ruiz, Stud. Surf. Sci. Catal. 112, 241 (1997).

21. T. V Choudhary, E. Aksoylu, and D. W. Goodman, Catal. Rev. 45, 151 (2003).

22. S. Luzan and A. Talyzin, Microporous Mesoporous Mater. 135, 201 (2010). 